\title{
Don Martín de Osambela, comerciante navarro de los siglos XVIII/XIX, y su descendencia en el Perú
}

\author{
Teodoro Hampe Martínez \\ Pontificia Universidad Católica del Perú
}

Esta contribución enfoca la biografía, los negocios mercantiles y las vinculaciones genealógicas de don Martín de Osambela (ca. 1754-1825), comerciante navarro, oriundo del pueblo de Huici, que se trasladó al virreinato del Perú y logró armar una sólida fortuna, estimada en medio millón de pesos. Hoy el recuerdo de Osambela ha quedado patente sobre todo en la soberbia casona de cuatro plantas que se hizo levantar, a principios del siglo XIX, en la ciudad de Lima. El presente estudio se ocupa también de las dificultades y la oscura muerte de Osambela, en medio de la guerra de la Independencia, y del destino que tuvieron sus propiedades (unas confiscadas y otras arruinadas) al pasar a manos de su esposa y sus hijos. A pesar de todo, el caso de don Martín de Osambela demuestra que no fueron pocos los empresarios residentes en el Perú que, salvando las trabas administrativas y los recortes de privilegios, consiguieron salir airosos de la introducción del régimen de libre comercio a fines del periodo virreinal.

En el humilde lugarejo de Huici, ubicado al noroeste de la comunidad foral de Navarra (España) y bañado por las aguas del río Larraun, vino al mundo hacia 1754 el protagonista de nuestro estudio: don Martín de Osambela y Osambela. Comerciante trasladado al virreinato del Perú, demuestra con la multiplicidad de sus negocios y la solidez de su fortuna (estimada en medio millón de pesos) que no fueron pocos los empresarios que, en estas tierras, lograron salir airosos de la introducción del régimen de libre comercio en $1778 .{ }^{1}$ El recuerdo de Osambela ha quedado patente sobre todo en la soberbia casona de cuatro plantas que se hizo levantar, a principios del siglo XIX, en la ciudad de Lima; pero su buena estrella se opacó abruptamente con la proclamación de la independencia por don José

$1 \mathrm{Cf}$. las impresiones que ofrecen al respecto Mazzeo, Cristina Ana: El comercio libre en el Perú. Las estrategias de un comerciante criollo: José Antonio de Lavalle y Cortés, conde de Premio Real, Lima, 1994, págs. 230-235, y sobre todo Rizo-Patrón Boylan, Paul. Linaje, dote y poder. La nobleza de Lima de 1700 a 1850, Lima, 2000, págs. 37-47 y 71-78. Señalan estos autores que, a pesar de las reformas administrativas y de la pérdida de los privilegios de Lima como eje de la distribución regional, siguió existiendo dentro de la élite mercantil limeña la capacidad para acumular grandes fortunas. Lo que sucedió más bien fue una recomposición al interior de la cúpula dirigente, en virtud de la cual dinámicos sectores de inmigrantes (vascos y navarros, especialmente) tomaron el protagonismo y se lanzaron a nuevas empresas. 
de San Martín y sus herederos vinieron a perder, además de la ostentosa morada, gran parte del devaluado patrimonio del fundador.

La presente investigación, realizada con un doble carácter social y genealógico, trata primeramente la biografía de don Martín de Osambela, el desarrollo de sus actividades comerciales y la consolidación de su patrimonio, tal como se manifiesta en numerosos documentos sobre casas y bienes raíces de su propiedad. Esta parte biográfica se ocupa también de las dificultades y la oscura muerte de Osambela, en medio de la guerra de la Independencia, y del destino que tuvieron sus propiedades - unas confiscadas y otras arruinadas - al pasar a manos de su esposa y sus hijos. El árbol genealógico presentado a manera de esquema exhibirá los entronques del linaje vasco-navarro de los Osambela, vinculados por la sangre y por negocios con varias otras familias conocidas de la misma procedencia; a continuación, una relación de documentos selectos (tomados del Archivo General de la Nación y de otros repositorios de Lima) expondrá testimonios de primera mano sobre la trayectoria de este importante hombre de negocios de los siglos XVIII/XIX y su posteridad. ${ }^{2}$

\section{Primera fase: la instalación en el Perú}

La constancia del bautizo de don Martín de Osambela y Osambela, realizado en la parroquia de Huici —en vascuence Uitzi- el 29 de agosto de 1754, significa la primera referencia histórica de nuestro personaje: el mayor de los siete hijos habidos en el matrimonio de don Martín de Osambela y Arregui y doña María Josefa de Osambela y Azpirroz (de la casa de Recaldea). Su padre era el dueño de la casa de Martiperenea en Huici, a la cual había accedido por herencia de su abuelo materno, don Martín de Arregui. Existía en el mismo pueblo una casa matriz de los Osambela, la cual se hallaba en poder de la rama agnaticia de la familia, los descendientes mayores de un Pedro de Osambela que figura hacia mediados del siglo XVII; pero ambas ramas vinieron a unirse nuevamente por el matrimonio, en 1791, de don Pedro Miguel de Osambela (hermano menor de don Martín) y doña María Miguel de Iriarte. Se dice que los contrayen-

2 Expreso mi sincera gratitud al señor Miguel A. del Castillo Morán, historiador egresado de la Universidad Nacional Mayor de San Marcos, por su valiosa ayuda en la investigación de los fondos manuscritos relativos a don Martín de Osambela y familia. 
tes debieron solicitar licencia especial por hallarse en "cuarto grado triplicado de consanguinidad". ${ }^{3}$

No están bien aclaradas las circunstancias de la venida de don Martín de Osambela al Perú - tierra de promisión tan mentada durante las generaciones precedentes-, hecho que debió de ocurrir alrededor de 1775. De acuerdo con César Pacheco Vélez, autor de la mejor aproximación biográfica al personaje, es de suponer que Osambela vendría a este país llamado por los Elizalde. ${ }^{4}$ El dato seguro es que su primer destino en el espacio peruano fue la ciudad de Arequipa, donde se sabe que mantuvo contacto con los Goyeneche. ${ }^{5}$ Gracias a los papeles de su archivo personal, que felizmente se han salvado en buena parte y están hoy en poder de sus descendientes en Lima, se puede formar un cuadro de sus negocios primigenios utilizando la correspondencia que sostuvo con su socio y representante en Moquegua, Diego Beltrán, de 1775 a 1778.

Manifiestan los documentos que don Martín enviaba paños, sedas, tafetanes, medias, ropa confeccionada, pasamanería y especias como pimienta de chapa a Moquegua y toda la vecina región del sur. Beltrán le correspondía con paltas y aceitunas. Escribe Pacheco Vélez: "Beltrán se mueve por Moquegua, Torata y otros valles de proverbial feracidad de la zona. Varias veces demora en los envíos de metálico a Lima; en cierta ocasión Osambela se los reclama desde Arequipa. El éxito de sus actividades comerciales se extiende por todo el sur del Bajo Perú y por el Alto Perú". ${ }^{6}$

El buen suceso en los negocios hizo que don Martín pronto viera la conveniencia de traer al Perú a su hermano segundo, don Miguel Ventura de Osambela, para que le ayudara en sus labores mercantiles. De hecho, ya en noviembre de 1781 encontramos una carta del joven Miguelcho (tal era su apelativo en vascuence) firmada desde Arequipa. ${ }^{7}$ Este hermano menor se

3 Véase la probanza de limpieza de sangre de don Miguel Ventura de Osambela, inserta en un volumen de traslados de "Reales cédulas de hidalguía y nobleza concedidas a los originarios del valle de Larraun" (fecho en Pamplona, 2 de noviembre de 1784). Se conserva en el archivo familiar de Luis Noriega Prentice.

4 Pacheco Vélez, César: "La casa de Martín de Osambela", en Memoria y utopía de la vieja Lima, Lima, 1985, pág. 190. Véase también Villa Esteves, Deolinda: "Liderazgo y poder: la élite comercial limeña entre el comercio libre y la guerra de la Independencia (el caso de Antonio de Elizalde)", en Los comerciantes limeños a fines del siglo XVIII; capacidad y cohesión de una élite, 1750-1825, Lima, 1999, págs. 133-173.

5 Véase la carta de Osambela a su primo (residente en Pamplona) Pedro Miguel de Arvilla, fecha en Arequipa, 29 de julio de 1777. Original en el archivo familiar de Cecilia Rospigliosi Prentice.

6 Pacheco Vélez: "La casa de Martín de Osambela", pág. 190.

7 Carta de don Miguel Ventura de Osambela a don Martín de Osambela, fecha en Arequipa, 6 de noviembre de 1781. Original en el archivo familiar de Cecilia Rospigliosi Prentice. 
constituyó en el brazo derecho de todas las operaciones financieras y contables de nuestro protagonista, aquel en quien depositaba toda su confianza y resultaba ser su albacea y heredero universal por su testamento otorgado en Lima en mayo de $1812 .{ }^{8}$ Pero algún accidente debió de cortar prematuramente la vida de don Miguel Ventura, y no volvemos a encontrar ninguna mención de él tras la carta personal del 26 de febrero de 1813 en la que don Martín de Osambela asienta con toda agudeza y desprendimiento:

\begin{abstract}
En medio de nuestra edad y achaques, que acaso nos precisarán a terminar aquí los últimos días, estamos convencidos los dos hermanos (y lo está todo europeo) de lo triste que nos es este suelo por las opiniones de ingratitud, desprecio y aborrecimiento con que se nos mira, y de que se han dado las pruebas más claras y decididas en las elecciones populares de electores de barrios, cuya memoria es un convencimiento claro de que jamás nos tendrán los patricios en el grado de hermandad y relaciones que realmente deben ser consecuentes a la existencia universal de cuantos tengan la cara blanca en América... ${ }^{9}$
\end{abstract}

Para 1793 existe constancia de que otro pariente cercano de Osambela, su primo Juan José (tal vez don Juan José de Iriarte), había venido al territorio peruano. En febrero de dicho año aparece firmando una carta en Cerro de Pasco, aunque se queja del inhóspito temple de este mineral y expresa su deseo de regresar a España. ${ }^{10} \mathrm{La}$ alusión a negocios de índole minera es una demostración más de la enorme paleta de actividades que desarrollaba nuestro personaje: en 1786 había recibido, a bordo del barco La Rosa proveniente de Guayaquil, un lote de 48 cargas — esto es, unas 3.880 libras- de cacao. ${ }^{11}$

De todo ello surge la impresión de que la red comercial de Osambela, al menos en los primeros años de su establecimiento en el Perú, se orientaba básicamente a nutrir el mercado interno. Trabajaba no sólo en la compra y recolocación de productos agrícolas y manufacturados dentro del país, sino también en la importación de materias como el cacao de Guayaquil y el cobre de Coquimbo, que distribuía eventualmente a los polos de desarrollo regional en el propio espacio peruano. Esto quedaría

8 Archivo General de la Nación, Lima [en adelante: AGN], Protocolos notariales (siglo XIX), n. ${ }^{\circ} 664$, fol. 84. Testamento otorgado ante Gaspar de Salas el 26 de mayo de 1812.

9 Carta de Osambela a don Juan José de Iriarte, residente en Cádiz, 26 de febrero de 1813. Copia en el archivo familiar de Luis Noriega Prentice.

10 Carta a don Miguel Ventura de Osambela, fecha en Cerro de Pasco, 18 de febrero de 1793. Original en el archivo familiar de Cecilia Rospigliosi Prentice.

11 Debo esta noticia a una gentil comunicación personal de Cristina Ana Mazzeo de Vivò, profesora de la Pontificia Universidad Católica del Perú. 
confirmado por un valioso Inventario de los deudores de Osambela, tomado de los libros que dejó el personaje al morir y que manifiesta las fechas, los nombres y los asientos de sus principales clientes: para los años tempranos - los que preceden a 1807- sabemos que sus lugares de colocación eran Paita, Lambayeque, Trujillo, Cajamarca, Pasco, Huancayo, Huamanga, Huanta, Lucanas, Arequipa, Ica y Lima, entre otros. ${ }^{12}$ Todo un enjambre de negocios a lo largo y ancho del virreinato.

Más aún, Lorenzo Huertas Vallejos —que acompaña unas notas biográficas a la investigación arqueológico-histórica del Instituto Nacional de Cultura sobre la casa de Osambela en Lima- certifica que los protocolos notariales de aquella época guardan "un sinnúmero de poderes que personas de La Paz, Arequipa, Huamanga, Palpa, Chachapoyas, Conchucos, Cajamarca, Trujillo, etc. entregan a don Martín de Osambela para el arreglo de diferentes transacciones comerciales....". ${ }^{13}$ Otro de los negocios en que también participó fue la fabricación y venta al menudeo de pan en la ciudad de Lima. Se trata de la casa-panadería de la calle de Granados (más tarde regentada por su hijo don José Valentín Osambela), la cual compró en agosto de 1790 por la suma de 22.629 pesos y 5 reales a don Francisco de Aizinena..$^{14}$

Si bien don Martín fue ascendiendo en la escala social de la aristocrática y cortesana metrópoli del Rímac, es un hecho tajante que jamás logró ocupar posiciones de importancia - como prior o cónsul- dentro del tribunal del Consulado. Quizá su condición de nuevo rico o parvenu se lo impediría. Pero está fuera de duda que gozó el aprecio de las altas esferas oficiales, sobre todo del virrey don José Fernando de Abascal, quien el 23 de enero de 1807 escribía a la corte real de Madrid poniendo en relieve las virtudes "patrióticas" de Osambela al haber asumido el compromiso de financiar una compañía de milicias urbanas de cazadores, formada por ochenta hombres y puesta bajo su mando con el rango de teniente coronel: eran las difíciles circunstancias de la guerra desatada con Inglaterra y había que responder con armas y dineros en fidelidad a la monarquía católica. ${ }^{15}$

12 El documento, al parecer incompleto, se titula exactamente "Inventario de los deudores de Osambela en los lugares que se designan, fechas de sus escrituras e importancia de sus empeños". Se conserva en el archivo familiar de Cecilia Rospigliosi Prentice.

13 Huertas Vallejos, Lorenzo: "Estudio histórico", en Investigación arqueológica histórica de la casa de Osambela (o de Oquendo) - Lima, Lima, 1981, págs. 73-74.

14 Ibídem, pág. 73.

15 Carta de Abascal al generalísimo don Manuel Godoy, príncipe de la Paz, Lima, 23 de enero de 1807. Copia en el archivo familiar de Cecilia Rospigliosi Prentice. 


\section{Los años de éxito: casas y negocios}

El año 1807 marca, en nuestra opinión, un punto de viraje más que simbólico en la biografía de don Martín de Osambela. No se trata únicamente del testimonio de gratitud que recibía (como acabamos de ver) de parte de las autoridades oficiales; aquí interviene en mayor término su asentamiento como poderoso señor de la ciudad de Lima a través de la erección de su notable mansión ubicada en la calle de la Vera Cruz, hoy segunda cuadra del jirón Conde de Superunda. ${ }^{16}$ El levantamiento de esta magnífica casona fue posible, ante todo, gracias a las óptimas relaciones de Osambela con los frailes de la orden de Santo Domingo, quienes en realidad le cedieron - por venta enfitéutica al plazo de 150 años - una parte de su "convento grande" dedicado a Nuestra Señora del Rosario. Dicha venta, efectuada el 16 de mayo de 1807 ante el escribano limeño Justo Mendoza y Toledo, comprendía el antiguo noviciado de los dominicos y una parte de la huerta del convento, que habían quedado en estado ruinoso luego del desolador terremoto de $1746 .{ }^{17}$

Por no hallarse con medios suficientes para reedificar aquella porción del convento, los frailes reunidos en capítulo (bajo la presidencia del maestro prior, fray Joaquín Molleda) decidieron entregar la finca al uso del rico comerciante Osambela. El terreno comprendía 38 varas de frente $(31,76 \mathrm{~m}$.) sobre la calle y 33 varas de fondo $(27,58 \mathrm{~m}$.) hacia el interior del convento y recibió el precio — bastante cómodo, en verdad - de 10.000 pesos; para satisfacer el derecho de uso de esta superficie, el adquiriente se comprometía a pagar sólo una renta de 300 pesos al año. La cláusula quinta del citado convenio fijaba que Osambela "ha de poseer la finca que labrase por el espacio de ciento cincuenta años y, finalizados estos, si el convento quisiere reasumirla, le ha de pagar la mitad del valor de lo labrado, a justa tasación". ${ }^{18}$

Con tan favorables condiciones, no tardó en levantarse allí, a dos cuadras de la plaza mayor de Lima, la espléndida morada del comerciante navarro, quien dio remate a la primera parte de la obra en el año 1808, tal como lo declara con orgullo una inscripción sobre la entrada principal. Poderosas influencias debió de mover don Martín a fin de que el cabildo municipal le ofreciera permiso para levantar un edificio de más de dos plantas, límite que

16 Antes de erigir esta casona, don Martín residía en una casa ubicada "en la calle de Santo Domingo, viniendo de la plaza mayor para el convento grande del Santísimo Rosario (Orden de Predicadores) a mano derecha, y antes del café conocido por el del Pini". Cf. Huertas Vallejos: "Estudio histórico"..., pág. 78.

17 AGN, Protocolos notariales (siglo XIX), n. ${ }^{\circ} 410$, fols. 291-297v.

18 Ibídem, fol. 294. 
se había estatuido en resguardo de los movimientos sísmicos: en efecto, la casona luce - todavía hoy - un tercer nivel sobre el portalón de entrada (con tres ventadas sobre la calle), y encima un gracioso mirador de traza octagonal y reminiscencias moriscas, rodeado de un largo barandal, el cual ha hecho las delicias de los cronistas y visitantes de la capital desde hace varias generaciones. ${ }^{19}$ Como lo hemos podido comprobar personalmente, dicho mirador sirve para observar la llegada de los barcos al puerto del Callao, ubicado a dos leguas de distancia.

Ya instalado en tan galana residencia, Osambela se empeñó en acrecentar el frente sobre la calle de la Vera Cruz con algunos solares anexos. En esa mansión tendría amplio espacio para atender sus negocios y para cobijar a su mujer y sus hijos, que empezarían a ver la luz del día, aunque fuera del sacramento matrimonial, a partir de 1810 (aproximadamente). No quedan muy evidentes las razones por las cuales nuestro personaje decidiera habitar en simple concubinato con una dama criolla, la limeña doña Mariana Ureta y Bermúdez, hija de don José Tadeo Ureta y doña Isabel Bermúdez. Los nombres de sus cinco primeros hijos - Mercedes, Mariana, José, Dolores y Cayetano- se revelan a través de su testamento otorgado el 21 de febrero de 1822, un mes después de haber contraído enlace por la Iglesia [ver árbol genealógico].

Las escrituras de última voluntad labradas sucesivamente por Osambela, no obstante ser escuetas respecto a sus actividades comerciales y su cúmulo de propiedades, contienen datos interesantes acerca de su devoción espiritual y las personas de su confianza. Tanto en el testamento de 1812 como en el de 1815 pide don Martín ser amortajado con el hábito y cuerda de la orden de San Francisco y manifiesta, además, su pertenencia a las cofradías o hermandades de Nuestra Señora de Aranzazu (propia de los inmigrantes vascos) y de Nuestra Señora del Rosario (vinculada a los dominicos). Una vez desaparecido su hermano don Miguel Ventura, por otro lado, decide nombrar como albaceas y herederos a dos individuos no emparentados con él, pero de su entorno más cercano: Francisco Mais y Miguel Antonio de Artola. ${ }^{20}$

19 Entre los que han representado gráfica o textualmente a la casa de Osambela se encuentran Léonce Angrand y Johann Moritz Rugendas, en el siglo XIX, y más modernamente devotos limeñistas como José de la Riva-Agüero, José Gálvez Barrenechea, Luis Antonio Eguiguren, Héctor Velarde y Juan Manuel Ugarte Eléspuru. Cf. Pacheco Vélez: "La casa de Martín de Osambela”, págs. 186 y 201-204.

20 AGN, Protocolos notariales (siglo XIX), n. ${ }^{\circ}$ 665, fol. 546v. Testamento otorgado ante Gaspar de Salas el 31 de agosto de 1815. 
De hecho, sabemos que aquellos años bajo el gobierno de los virreyes Abascal y Pezuela (de 1806 a 1821) enmarcaron la definitiva consolidación del patrimonio de don Martín. Llegó a adquirir de los frailes dominicos - por repetidas concesiones enfitéuticas - una casa en la calle de Santa Rosa de los Padres, un callejón de cuartos (con dos casitas accesorias) en la calle de las Cabezas y otro callejón en la Toma de Santo Domingo. La historia recoge además la versión, transmitida originalmente por Sánchez Carrión, de que Osambela tuvo la suerte de ganar jugando a las cartas la huerta nombrada de la Menacho, en el valle de Ate. ${ }^{21}$ Dicha huerta, que por sus numerosos aperos, criados y próspero estado habría valido unos 60.000 pesos, pertenecía nada menos que a don José Baquíjano y Carrillo, el prócer de la Emancipación.

Entre los papeles de Osambela que han quedado en poder de sus descendientes se encuentra, afortunadamente, un legajo con copias de cartas destinadas al extranjero y fechadas entre 1807 y 1813. César Pacheco Vélez, quien vio este interesante conjunto de documentos, destaca la valía de las transacciones efectuadas con hombres de negocios de Hamburgo (Brentano y compañía), Madrid (don Juan Bautista de Irribaren) y Cádiz (don Juan José de Iriarte y los señores Micheo, padre e hijo), a los cuales se remitía productos "de la tierra" como cacao, cobre, cascarilla y lana de vicuña. ${ }^{22}$ Sólo una de las operaciones aludidas en dichos papeles, la relativa al cargamento del navío hamburgués Wilhelmburg, que traía manufacturas europeas para el mercado de Lima, representa la suma de 436.702 pesos y 4 reales. ${ }^{23}$

Bien se deja comprender que esa expectante posición del individuo dentro del gremio de mercaderes de Lima se tradujera en exigencias de cuotas y contribuciones a favor de la Corona. Así tenemos que en el año 1817 el virrey don Joaquín de la Pezuela le intimaba, por sendos oficios

21 Decía, con no poca inquina, don José Faustino Sánchez Carrión: "Y averiguando sobre la finca que pueda contenerlos [se refiere a un premio de 30.000 pesos], he encontrado proporcionada la huerta de la Menacho del español don Martín de Osambela, que con toda su familia está en el Callao. Esta finca fue de Baquíjano, y la perdió al monte en una sola carta jugando con Osambela...”. Oficio al Libertador Bolívar fecho en Lima, 17 de marzo de 1825; publicado en Tamayo Vargas, Augusto, y Pacheco Vélez, César (comp.): José Faustino Sánchez Carrión [= Colección documental de la Independencia del Perú, tomo I, vol. 9], Lima, 1974, pág. 291.

22 Pacheco Vélez: "La casa de Martín de Osambela”, págs. 192-194.

23 Las noticias más detalladas acerca del navío Wilhelmburg (su capitán, Daniel Jacobo Luben) se encuentran en la carta de Osambela a los señores Brentano, Bovara y Urbieta fecha el 28 de diciembre de 1807. Refiere aquí que el cargamento vino acompañado por C.W. Juan Heyland, un agente de la compañía hamburguesa, y que ante la imposibilidad de hallar un buen comprador para la mercadería en conjunto se determinó a "vender por partes, según se presentasen las ocasiones, y en efectos". 
cursados el 28 de marzo y el 8 de octubre, la necesidad de aportar 960 pesos al semestre, con el objeto de armar la defensa de los "derechos soberanos" frente a la subversión que significa la invasión de las tropas de San Martín a Chile..$^{24}$ La posición rotunda de don Martín de Osambela a favor de la causa realista queda patente, por lo demás, en varias declaraciones de su correspondencia privada.

Ya producido el definitivo alejamiento de don José Fernando de Abascal, el comerciante navarro prosiguió en contacto con el antiguo vicemonarca durante sus últimos años de vida en España (donde fungió como miembro del Consejo de Guerra). Así lo evidencian unas cartas para Abascal, hoy guardadas en el Archivo General de Indias de Sevilla, que don Martín le envió el 13 de julio de 1818 y el 9 de julio de 1819; en ellas informaba sobre la "pérdida" de la capitanía general de Chile y daba noticias frescas sobre la administración — bastante discutida - de Pezuela..$^{25} \mathrm{Si}$ nuestro personaje se empeñó en guardar esa vinculación con Abascal, fue tal vez porque cifraba en el poderoso ex virrey la esperanza de obtener algún título nobiliario del reino de Navarra, como se le había ofrecido ya durante los años de la invasión napoleónica a España. ${ }^{26}$

\section{El ocaso: la guerra de la Independencia}

Por cierto que don Martín de Osambela quedó sin el honroso premio de un título nobiliario, quizá debido a la ingerencia negativa de algunas personas de Lima, y principalmente de don Gaspar Rico, "mi decidido enemigo - como él mismo lo reconoce-, por opuesto en las juntas de Consulado y otras ocurrencias". ${ }^{27}$ Pero su calidad de hombre solvente no pasó desapercibida a los dirigentes del triunfante bando patriota, que tomaron las riendas del poder luego de la proclamación de la Independencia el

24 Ambos oficios de Pezuela se conservan, originales, en el archivo familiar de Cecilia Rospigliosi Prentice.

25 Ambas cartas de Osambela se conservan, originales, en el Archivo General de Indias, sección Diversos, leg. 5, ramo 1, bajo los núms. 44 (la de 9 de julio de 1819) y 59 (la de 13 de julio de 1818).

26 Está consignado así en una carta de Osambela para don Juan José de Iriarte (residente en Cádiz), fecha el 15 de mayo de 1812: "[Abascal] informa a Su Majestad de mi extraordinario servicio y de otros de buen vasallo, solicitando se me haga la gracia de un título de Navarra". Véase también Pacheco Vélez: "La casa de Martín de Osambela", pág. 192.

27 Carta a don Juan José de Iriarte fecha el 15 de mayo de 1812, arriba citada (en el archivo familiar de Luis Noriega Prentice). 
28 de julio de 1821 y de la instalación del gobierno protectoral de don José de San Martín. En fecha tan temprana como el 1 de agosto siguiente, el Protector se dirigió al tribunal del Consulado de Lima, reclamando un empréstito urgente (mejor dicho, una donación) por el valor de 150.000 pesos. Osambela fue desde luego llamado a brindar una aportación junto con los demás mercaderes, representando su cuota de 1.000 pesos una fracción de tan sólo 0,66 por ciento. ${ }^{28}$

Las dificultades con el nuevo régimen comenzaron en serio desde enero de 1822 , debido a la política crecientemente antiespañola del ministro de Guerra y factotum sanmartiniano, Bernardo Monteagudo. En dicho mes se decretó la expulsión de los hombres solteros que no poseyeran "carta de ciudadanía", a quienes se incautaría la mitad de sus bienes para la causa patriota..$^{29}$ Fue ante tal amenaza, seguramente, que don Martín de Osambela y doña Mariana Ureta se apresuraron en formalizar su unión conyugal: asistieron el 14 de enero a la iglesia parroquial del Sagrario de la Catedral para ser casados por fray José Santiago Polar, llevando como testigos a dos personajes de origen vascuence (y probablemente emparentados con Osambela), el teniente coronel Juan Aspiruz y don Francisco Iriarte. ${ }^{30}$

Es de suponer, además, que ante el riesgo de perder los bienes legalmente declarados, los contrayentes prefiriesen no otorgar una carta formal de dote. En todo caso, al hacer su testamento en julio de 1843, recordará doña Mariana que llevó por caudal propio "un principal de diez mil y más pesos en efectos de mantería que tenía en una tienda en la calle del Arzobispo [...], y también llevé dos esclavos y una esclava, con más cerca de novecientos pesos en alhajas"; ${ }^{31}$ bienes que posteriormente se tomarían en cuenta, al discutir y ejecutar la repartición del patrimonio de Osambela y su esposa entre los seis hijos. Se considera por cierto que la fortuna de nuestro protagonista había llegado a su punto más alto en 1821, con la proclamación de la Independencia, y los peritos judiciales dirán que valía entonces medio millón de pesos. ${ }^{32}$

28 Cf. Tauro, Alberto (comp.): Informes y oficios del tribunal del Consulado [= Colección documental de la Independencia del Perú, tomo XXI, vol. 1], Lima, 1971, págs. 375 y 417.

29 Pacheco Vélez: "La casa de Martín de Osambela", pág. 196.

30 Parroquia del Sagrario, Lima. Libro de Matrimonios, 1822, fol. 277.

31 AGN, Protocolos notariales (siglo XIX), n. ${ }^{\circ}$ 968, registro de Manuel de Uriza, fol. 473. Testamento otorgado ante José Matías Delgado el 5 de julio de 1843.

32 "Es, pues, indudable que don Martín al enlazarse con doña Mariana Ureta poseía una ingente fortuna, cuyo importe excedía de medio millón de pesos...”, según el laudo arbitral del doctor Antonio Arenas, otorgado en Lima el 31 de marzo de 1870. AGN, Protocolos notariales (siglo XIX), n. ${ }^{\circ} 863$, registro de Félix Sotomayor, fol. 1620. 
En tal contexto, don Martín — quien nunca había dejado de manifestar sus simpatías por la bandera del rey-cayó en la ojeriza de los sectores oficiales, y sobre todo de Monteagudo, el cual no desaprovechaba ocasión para criticar y esquilmar a "los despreciables y malvados chapetones". Sabemos concretamente que el 13 de abril de 1822 se requirió una donación especial de 110.000 pesos al conjunto de los españoles residentes en la ciudad de Lima. ${ }^{33}$ "De los 130 obligados donantes — precisa Pacheco VélezOsambela aparece entre los veinte principales con 1.700 pesos, antecedido por Juan Bautista Sarraoa, Mariano de Aramburú, Simón de Rávago (que fue secretario de Abascal), Bartolomé María Salamanca, los Sainz de Tejada, José Matías de Elizalde, José Blanco y Azcona y otros....". ${ }^{34}$ Esta vez, dicho sea de paso, ascendía la proporción de su aporte al 1,54 por ciento.

Las relaciones de Osambela con el nuevo poder ejecutivo se hicieron tan críticas, que le tocó perder inclusive su colección particular de libros. Hasta ahora se había difundido la noción — transmitida por Estuardo Núñez a base de una relación de gastos ubicada en el Archivo General de la Nación - de que don Martín había contribuido generosamente a las colecciones iniciales de la Biblioteca Nacional de Lima, remitiendo de su propia voluntad un par de carretadas de libros que tenía en su mansión de la calle de la Vera Cruz. ${ }^{35}$ Sin embargo, la compulsa de la documentación original nos induce a pensar más bien que aquí se dio una intervención violenta de los agentes del Estado, tal como se manifiesta en una denuncia elevada en septiembre de 1827 por la viuda, doña Mariana Ureta de Osambela, a las autoridades del Congreso de la República:

Tampoco se tuvieron presentes los empréstitos que hizo al Estado Osambela, ni el valor de la biblioteca que le usurpó el ministro Monteagudo. Constaba ésta de más de 15 mil volúmenes, de los autores más clásicos, de preciosos manuscritos y de sobresalientes grabados; y es la misma con que se abrió la Biblioteca Nacional y en donde subsiste hasta ahora, como puede asegurarlo el señor diputado [Mariano José de] Arce, a cuyo cargo estuvo aquel establecimiento. Esta partida es de la mayor consideración por su valor, como que Osambela había ajustado la venta de toda la biblioteca con el señor arzobispo de La Plata el año de 820 en la cantidad de 30 mil pesos, cuyo convenio no pudo realizar por las posteriores ocurrencias. ${ }^{36}$

33 Puente Candamo, José A. de la (comp.): Obra de gobierno y epistolario de San Martín, I [= Colección documental de la Independencia del Perú, tomo XIII, vol. 1], Lima, 1974, págs. 181-184.

34 Pacheco Vélez: "La casa de Martín de Osambela", pág. 196.

35 Núñez, Estuardo: "Mariano José de Arce, primer bibliotecario", en Fénix/revista de la Biblioteca Nacional, vol. 21, Lima, 1971, pág. 51, nota 8.

36 Recurso de doña Mariana Ureta de Osambela ante la comisión de Justicia del Congreso de la República, Lima, 4 de septiembre de 1827. 
Se podría dudar algo de esta declaración sobre el valor y la riqueza de la colección de libros reunida por el empresario navarro, un hombre a quien no le conocemos en principio mayores inclinaciones académicas o veleidades intelectuales. Habría que pensar entonces, de preferencia, en una biblioteca de ornamentación doméstica y en un eventual lugar de tertulia o reunión para la gente letrada. Lo cierto es que la pendencia judicial sobre el embargo de aquellos libros continuó por muchos años, y todavía era mencionada por los herederos de nuestro personaje en fecha tan remota como 1892 (como se ve en el testamento de su hija doña Dolores). ${ }^{37}$

En los expedientes levantados por el juzgado de secuestros en la época de la Independencia, se registra que para enero de 1825 la casa de Osambela en Lima había sido evacuada por don Martín y su familia y se había dado en alquiler - con sus ocho tiendas y cochera accesorias - al extranjero Mr. John Begg, probablemente un inglés. ${ }^{38}$ Es que para entonces la familia Osambela había optado por refugiarse en los castillos del vecino puerto del Callao, uniéndose al general José Ramón Rodil y a otros tercos defensores del estandarte borbónico. Debemos tener en cuenta que la persecución antiespañola había tomado caracteres más drásticos al producirse la vuelta al poder de Monteagudo, quien había sido rechazado por un levantamiento popular en 1822, pero regresó nuevamente bajo el amparo de Bolívar. ${ }^{39}$

Respondiendo a la emigración de la familia Osambela al Callao, los jefes de la dictadura bolivariana procedieron al secuestro de todos sus bienes (que fueron avaluados en 198.860 pesos) y a la confiscación de la quinta parte de ellos. Para integrar este quinto se adjudicó al Estado la casa ubicada junto al santuario de Santa Rosa de Lima —en la calle de Santa Rosa de los Padres - y la finca de la Menacho, en el valle de Ate, que ya hemos mencionado. El 23 de abril de 1825 fue expedido un decreto ordenando la adjudicación de dicha finca al "tribuno de la República", don José Faustino Sánchez Carrión, como premio a sus servicios por la causa emancipadora y para compensación de su sueldo como ministro de Gobierno y Relaciones Exteriores $;{ }^{40}$ debido al deterioro que había sufrido esta propiedad en medio

37 AGN, Protocolos notariales (siglo XIX), n. ${ }^{\circ} 792$, fol. 1908v. Testamento otorgado ante Carlos Sotomayor en Lima, el 22 de junio de 1892.

38 AGN, Juzgado de secuestros, leg. 472, fol. 1.

39 Cf. Basadre, Jorge: Historia de la República del Perú, 1822-1933, Lima, 1983, vol. 1, págs. 61-62 y 152-153, y McEvoy Carreras, Carmen: "El motín de las palabras: la caída de Bernardo Monteagudo y la forja de la cultura política limeña (1821-1822)", en Forjando la nación; ensayos sobre historia republicana, Lima, 1999, especialmente las págs. 32-47.

40 Barra, Felipe de la (comp.): Estado militar, años 1824-1826 [= Colección documental de la Independencia del Perú, tomo VI, vol. 8], Lima, 1973, págs. 250-251. 
de las guerras y de los desórdenes internos, fue tasada oficialmente en 20.171 pesos y 5 reales. Al hacerse cargo de la huerta perteneciente a Osambela, expresaba Sánchez Carrión con el mayor cinismo:

...después de muchas meditaciones y perplejidades, me he resuelto a esta indicación, porque ya que se me proporciona una finca, quisiera fuese en el campo, por ser muy conforme con mi espíritu este género de entretenimiento y como porque su producto es más seguro que el de las fincas urbanas. ${ }^{41}$

La familia Osambela-Ureta había aumentado después del matrimonio de 1822 con el nacimiento de la pequeña doña Juana. Seis hijos menores de edad se hallaban, pues, junto a doña Mariana cuando se produjo, en fecha no determinada, la muerte del desdichado don Martín de Osambela y Osambela, presuntamente a los 71 años de edad. Arrinconado en el mayor ostracismo político y en una exasperante pobreza, el próspero hombre de negocios oriundo del valle de Larraun que logró "hacer la América" con un activo comercio en el espacio tardovirreinal peruano, desapareció en el Callao durante el año 1825 y fue enterrado, probablemente, en las costas de Pacifico junto a la fortaleza del Real Felipe. ${ }^{42}$ Así terminó, sombría y patéticamente, la existencia de nuestro personaje.

\section{La casa de Osambela y su destino}

Los aires políticos volvieron a cambiar en 1826, con la caída de la dictadura de Bolívar y el término definitivo de la resistencia española en el Callao. Entonces doña Mariana Ureta trató de poner en ejecución una ordenanza (de 2 de marzo del año anterior), que le permitiría recuperar los bienes secuestrados a su difunto esposo, pagando el quinto de su valor monetario. ${ }^{43} \mathrm{Al}$ iniciar una larga serie de tramitaciones con el objeto de retrotraer aquel patrimonio al magnífico estado que había poseído, escribía la viuda a los miembros de la comisión de Justicia del Congreso de la República: "Y aun en las naciones beligerantes civilizadas, después de concluida la guerra, siempre es admitida la devolución de propiedades, cuando prueban no haber tenido parte activa en los sucesos. Así es practicado en las más

41 Tamayo Vargas y Pacheco Vélez (comp.): José Faustino Sánchez Carrión..., pág. 291.

42 Pacheco Vélez: "La casa de Martín de Osambela", pág. 199.

43 AGN, Juzgado de Secuestros, leg. 473. Recurso de doña Mariana Ureta de Osambela pidiendo la devolución de sus bienes, "en atención a habérseme alzado el secuestro" (por decreto supremo del 31 de julio de 1826). 
cultas, como lo manifiestan los papeles públicos de la Europa en sus antiguas y recientes disensiones". ${ }^{44}$

Los primeros objetivos de restitución en el patrimonio de Osambela fueron la casa de Santa Rosa de los Padres y la huerta de la Menacho, confiscadas ambas durante la época triunfal de Sánchez Carrión y el bolivarismo, y cuyo valor en conjunto se tasó a 37.000 pesos. Como quiera que los gobiernos de la naciente República no se avinieron a admitir sus ruegos en pos de una restitución gratuita, doña Mariana se vio obligada a contraer un préstamo especial, ya que ella misma se encontraba ocupada con la crianza de sus menores hijos y había dejado en suspenso los negocios de su marido (quien habría dejado — según se dice- un lote espectacular de 600.000 pesos en deudas por cobrar). Así fue que la viuda de Osambela pactó con el clérigo don Pedro Salvi, cura de la doctrina de Tapo, un empréstito de 16.000 pesos al interés de 1,5 por ciento mensual. ${ }^{45}$

Si bien se logró con ese dinero el objetivo inmediato de restituir al patrimonio familiar ambos bienes mencionados $-\mathrm{y}$ doña Mariana Ureta vino a fallecer inclusive en aquella morada junto al santuario de Santa Rosa-, el costo del préstamo contraído con el cura Salvi resultó mucho más alto, impensadamente oneroso. Y es que, hallándose la atribulada señora en incapacidad de cubrir los réditos devengados por la suma de 240 pesos mensuales, apareció en escena la persona que heredó los bienes de Salvi y dijo ser la verdadera financista del empréstito: doña Manuela Mesa y Gallegos, natural y vecina de Lima, casada al final de sus días (1854) con don Francisco Antonio de Goytisolo. Desde febrero de 1837, doña Manuela emprendió acciones judiciales para cobrar dichos réditos, señalando que los herederos de Osambela habían puesto como garantía su imponente mansión de la calle de la Vera Cruz, que por entonces estaba arrendada a una firma extranjera, la casa Read. ${ }^{46}$

Dado que la situación de la testamentaría Osambela, a cargo de la bien intencionada pero poco ejecutiva doña Mariana, no mejoraba en absoluto (sino más bien lo contrario), un auto judicial del 11 de enero de 1840

44 Recurso de doña Mariana Ureta de Osambela ante la comisión de Justicia del Congreso de la República (1827), ya citado en nota 36.

45 Huertas Vallejos: "Estudio histórico"..., págs. 79-80.

46 Ibídem, pág. 80. Véase también AGN, Protocolos notariales (siglo XIX), n. ${ }^{\circ}$ 164, registro de Juan Cosio, fol. 109 y ss., donde se transcriben los autos promovidos por doña Manuela Mesa desde la escritura de obligación otorgada a su favor, el 1 de febrero de 1837, por doña Mariana Ureta. Es de notar, por cierto, que el inglés Thomas Wheelock (uno de los hijos políticos de doña Mariana) trabajaba como empleado de la casa Read, arrendataria de la mansión de Osambela. 
mandó embargar a favor de doña Manuela Mesa los arriendos de la casa de Osambela ${ }^{47}$ En este contexto, se dispuso una visita y tasación de la finca, que ejecutaron los peritos ingenieros Juan de Herrera e Isidoro Nieves. El documento original de la tasación, fechado el 31 de octubre de 1840, es sumamente interesante y ha sido publicado casi íntegramente por Lorenzo Huertas Vallejos. Los peritos descomponen su examen en la parte baja y en los altos de la casona; señalan que ésta "tiene de frente 57 varas tres cuartas [unos 47,3 m.] y en ellas diez puertas a la calle, que son la principal, ocho accesorias y una cochera, todas con sus altillos" y destacan, entre otros aspectos, las características de la escalera principal, "que está en el patio y gira por encima de la cochera". ${ }^{88}$ El valor neto indicado para la finca, descontadas las cargas del contrato enfitéutico con el convento de Santo Domingo, fue de 69.984 pesos y 1,25 reales.

De ahí en más, los esfuerzos de doña Mariana Ureta y sus hijos (en verdad poco colaboradores) se concentraron en evitar la pérdida de la emblemática residencia, el testimonio más visible de la exitosa carrera empresarial de don Martín de Osambela en las Indias. Como parte de su estrategia - ya que realmente, a mi parecer, no lo era- la viuda fue declarada el 26 de enero de1842 absolutamente insolvente, o sea "pobre de solemnidad" ${ }^{49}$ Es cierto que ella había gastado sus alhajas en brindar una moderada dote para el matrimonio de sus hijas (doña Mercedes, casada con José Negrete, doña Mariana, con José Ignacio Riera, y doña Juana, con Juan Bautista Vera), pero aún quedaban en su poder todas las casas, callejones y fincas que había dejado su primer marido. Además, consta por los papeles de archivo que la señora Ureta — casada en segundas nupcias con el doctor José Miguel Berasar- poseía el tambo y huerta de las Huaquitas, cerca de la portada de Maravillas, y una tienda o cajón en el portal de Botoneros, frente a la plaza mayor de Lima. ${ }^{50}$

Infructuosas gestiones realizó doña Mariana Ureta para que la casa de Osambela se pusiera a remate o fuera entregada a rifa. La situación no estaba absolutamente resuelta cuando ella otorgó ante notario sus expresiones de última voluntad, en julio de 1843, y expiró poco después. Sin mayor éxito en

47 Dicho auto fue confirmado por otro del 7 de abril de 1842, en que "se le adjudica a doña Manuela Mesa los arrendamientos de la finca secuestrada". AGN, Corte Superior de Lima, Causas civiles, leg. 386, cuad. 2, fol. 20v.

48 Huertas Vallejos, "Estudio histórico"..., págs. 80-85.

49 AGN, Corte Superior de Lima, Causas civiles, leg. 386, cuad. 2, fol. 36.

50 AGN, Protocolos notariales (siglo XIX), n. ${ }^{\circ}$ 968, registro de Manuel de Uriza, fol. 477. Codicilo otorgado por doña Mariana Ureta ante José Matías Delgado el 6 de julio de 1843. 
el sostenimiento de las deudas contraídas, los seis hijos de don Martín de Osambela se limitaron a aceptar que la mansión familiar fuera ofrecida en pública subasta, a partir de 1848, por dos y hasta tres veces. Pero como no hubo postores con ofertas dignas de tomar en cuenta, un auto judicial del 13 de abril de 1853 dispuso que la casa pasara a manos a doña Manuela Mesa, bajo la condición de abonar las dos terceras partes del valor de su tasación..$^{51}$

Así fue que el 12 de junio de 1854, habiendo satisfecho dicha señora la paga taxativa de 46.656 pesos, una resolución del juzgado de primera instancia a cargo del doctor Manuel Olivares sancionó la pérdida definitiva de la casa de la Vera Cruz para la familia Osambela. ${ }^{52}$ Por no tener descendientes, doña Manuela Mesa — quien falleció apenas cinco meses después de haber adquirido la finca - instituyó como heredero en esta propiedad al doctor Manuel de la Ascensión Oquendo. ${ }^{53}$ La posterior instalación de la familia Oquendo no trajo excesivas modificaciones en la estructura de esa señorial residencia, que había sido labrada para acoger los gustos y las exigencias de nuestro protagonista, incluyendo el orgulloso mirador de la cuarta planta para vigilancia de sus embarcaciones en la rada del Callao. Los actuales ocupantes de la finca, una serie de instituciones académicas y de cooperación peruano-española que forman el Centro Cultural Inca Garcilaso de la Vega, se precian de tener buena memoria y denominan a su sede como "la mansión de Osambela-Oquendo". ${ }^{54}$

\section{Legado a la posteridad: pendencias de bienes}

Perdida irremisiblemente aquella residencia, quedó también en cierta manera olvidado el apellido de Osambela en la sociedad capitalina. No se puede afirmar que los hijos del desdichado don Martín tuvieran una figuración prominente en la Lima del ochocientos, pues quedaron sumidos en

51 AGN, Corte Superior de Lima, Causas civiles, leg. 386, cuad. 2, fols. 89-92 y 128-130v.

52 AGN, Protocolos notariales (siglo XIX), n. ${ }^{\circ} 164$, registro de Juan Cosio, fols. 154v-157.

53 AGN, Protocolos notariales (siglo XIX), n. ${ }^{\circ}$ 164, registro de Juan Cosio, fols. 508-510. Testamento cerrado de doña Manuela Mesa y Gallegos, hija de don Juan Mesa y doña María Gallegos, otorgado en Lima el 12 de octubre de 1854. Dicho testamento se abrió ante el escribano Juan Cosio el 2 de diciembre del mismo año, fecha de la muerte de la señora Mesa (fol. 517).

54 El Centro Cultural Inca Garcilaso de la Vega, hoy una dependencia oficial del Ministerio de Educación, fue constituido por el decreto-ley 22.677 (de 10 de septiembre de 1979) y conformado originalmente por estas instituciones: la Academia Peruana de la Lengua, la Academia Nacional de la Historia, la Oficina de Educación Iberoamericana, el Instituto Peruano de Cultura Hispánica, el Patronato del Colegio Mayor San Martín de Porras, la Asociación Hispano-Peruana de Profesionales y la Comisión Mixta Peruano-Española de Intercambio Cultural. 
modestas capas medias, nota de la cual sólo se salva quizá la segunda de sus hijas, doña Mariana Osambela y Ureta, que fue casada sucesivamente con dos inmigrantes extranjeros: primero el tucumano José Ignacio Riera (1830) y luego el inglés Thomas Wheelock (1837). Acerca de este último personaje, sabemos que era nativo de Market Drayton, en Shropshire, y que estuvo radicado por varias décadas en la ciudad de Lima, pero regresó a su patria para morir en 1890 en Londres.

Por la documentación del Archivo General de la Nación sabemos que durante años mantuvo Wheelock en Lima una serie de pendencias judiciales; una de éstas fue con don Juan Blanco y Pérez, albacea testamentario de doña Mariana Ureta, por el ejercicio del albaceazgo de la testamentaría Osambela y por los pagos y demás beneficios de aquella herencia. ${ }^{55}$ Por otra parte, apreciamos que Wheelock - quien había empezado como empleado de la casa Read - mantenía intereses económicos en Lima y en algunas localidades del interior (como Cerro de Pasco, por ejemplo). Está comprobado que durante el año 1854, exclusivamente, invirtió más de 80 mil pesos en la compra de bienes raíces en el ámbito urbano de Lima, el balneario de Chorrillos y el valle de Ate. Este hombre de negocios inglés fue, además, representante de la casa comercial Bates, Stokes \& Co. (afincada en el Perú desde los años 1850), presidente del directorio de la Compañía de Alumbrado por Gas de Lima y Callao y accionista de la Empresa de Agua de Lima; y se dedicó corrientemente al préstamo de dinero con intereses..$^{56}$

Sea por causa de tan pujante actividad económica, o por cualquier otro motivo, lo notorio es que la rama familiar de doña Mariana Osambela y Ureta fue la que se quedó con los documentos del archivo personal de don Martín. Éstos pasaron en la segunda mitad del siglo XIX a manos del empresario Alexander Prentice, escocés de origen y marido de doña Rosa Riera y Osambela (nieta de nuestro protagonista). Modernamente, hemos podido consultar aquellos papeles - cartas privadas, partidas sacramentales, libros de cuentas y otros- gracias a la amabilidad de dos bisnietos de Prentice y choznos del fundador de la casa de Osambela en Lima: doña Cecilia Rospigliosi Prentice y don Luis Noriega Prentice. ${ }^{57}$

55 AGN, Corte Superior de Lima, Causas civiles, leg. 408, cuad. 5. Expediente seguido de 1844 a 1847.

56 Tomamos estos datos sobre la actividad empresarial de Thomas Wheelock de sus múltiples apariciones en los protocolos del escribano Juan Cosio, hacia mediados del ochocientos. Véase AGN, Protocolos notariales (siglo XIX), n. ${ }^{\circ} 160$ a 168, años 1846 a 1859.

57 Expreso aquí mi sincera gratitud a la señora Rospigliosi y el señor Noriega por las amables facilidades que me brindaron para trabajar en su archivo familiar. 
Como ya está dicho, los engorrosos y dispendiosos trámites judiciales llevados a cabo por los herederos de Osambela corrieron aparejados con una considerable disminución del patrimonio familiar, el cual si bien se mantuvo casi en número de propiedades, quedó enteramente reducido en cuanto a su valor monetario. Es obvio que "don Martín de Osambela, cuando contrajo matrimonio con doña Mariana, tenía un caudal muy superior a la masa de bienes que se encontró al tiempo de su fallecimiento", y después de su fallecimiento la ingente fortuna quedó reducida a "un valor sumamente inferior", según anota el doctor Antonio Arenas en su laudo arbitral de 1870, estableciendo la partición definitiva de la masa hereditaria entre los seis hijos. ${ }^{58}$ Con mejor razón para estar quejoso, uno de los hijos políticos de Osambela, don Juan Bautista Vera, había manifestado previamente en una diligencia judicial:

...en los largos años que hasta el presente han transcurrido a la muerte de don Martín de Osambela, nada se ha hecho por parte de los herederos para que la testamentaría llegue a su término. Cada interesado, consultando únicamente su bien individual, ha procurado la indivisión de los bienes hereditarios; y unas veces sembrando la discordia entre los miembros de la misma familia, y otras promoviendo cuestiones maliciosas e ilegales, han conseguido establecer un desorden espantoso para sacar cada uno [...] las ventajas que necesariamente trae consigo la confusión y el abandono en que hoy se encuentran los bienes. ${ }^{59}$

Finalmente se llegó a un acuerdo entre los seis coherederos (y una más, doña Tomasa Berasar y Ureta, si consideramos asimismo la herencia de doña Mariana Ureta en su segundo compromiso) para efectuar la tan ansiada repartición del patrimonio legado desde la guerra de la Independencia. El laudo correspondiente está signado el 31 de marzo de 1870 por el árbitro componedor, Antonio Arenas, y elevado a rango normativo por un auto judicial de 20 de abril del mismo año. ${ }^{60} \mathrm{Se}$ fija en este documento que el caudal de bienes de la testamentaría Osambela asciende a 95.680 pesos y que la parte correspondiente a la esposa, doña Mariana, llega al monto de 13.938 pesos (convirtiendo a esta moneda las cantidades que el laudo arbitral indica en soles).

Entre los bienes propios de don Martín de Osambela, tenemos que: [1] la huerta de la Menacho fue adjudicada en cinco partes iguales a sus hijos

58 AGN, Protocolos notariales (siglo XIX), n. ${ }^{\circ}$ 863, registro de Félix Sotomayor, fol. 1620.

59 AGN, Corte Superior de Lima, Causas civiles, leg. 669, cuad. 3, fol. 3. Recurso presentado el 1 de octubre de 1857 por José Manuel Manzanilla, procurador de don Juan Bautista Vera y su esposa, doña Juana Osambela. 
don José, don Cayetano, doña Dolores, doña Mariana y doña Juana Osambela, y una parte mayor para doña Mercedes; [2] la casa de la calle de la Recoleta fue adjudicada, en partes diferenciales, a doña Mercedes y doña Mariana; [3] el callejón de la Toma de Santo Domingo fue adjudicado en dos mitades a don José y don Cayetano; [4] la casa-panadería de la calle de Granados fue adjudicada, casi en su totalidad, a doña Juana; y [5] la casa de la calle de Santa Rosa de los Padres fue adjudicada, como única beneficiaria, a doña Dolores. ${ }^{61}$ Quedan fuera de este cómputo los bienes propios de doña Mariana Ureta, incluyendo sus derechos sobre una pequeña casa en la calle del Carmen Alto de Lima, que se traspasaron conforme a su voluntad testamentaria a la única hija de su segunda matrimonio, doña Tomasa Berasar y Ureta (casada dos veces y afincada en París, donde falleció en 1912). ${ }^{62}$

Tal es, en apretada síntesis, la historia infeliz y compleja del patrimonio labrado por el comerciante navarro don Martín de Osambela durante los años postreros del dominio español en el Perú; un patrimonio legado a su descendencia, a pesar de las vicisitudes económicas y de los cambios políticos, en el período de la bonanza del guano. Los principales datos biográficos y sociales del linaje de Osambela, con un esquema de los ascendientes de don Martín en cuatro generaciones, y de sus descendientes en otras tantas más, se pueden ver en el árbol genealógico que presentamos a continuación. ${ }^{63}$

60 AGN, Protocolos notariales (siglo XIX), n. ${ }^{\circ}$ 860, registro de Félix Sotomayor, fol. 312v. Protocolización efectuada el 4 de junio de 1870.

61 AGN, Protocolos notariales (siglo XIX), n..$^{\circ} 863$, registro de Félix Sotomayor, fols. 16281631.

62 Debo las noticias genealógicas sobre la familia Berasar-Ureta a una gentil información de monseñor Fernando Lamas Pereyra de Castro, prelado de honor de Su Santidad, residente en Ginebra.

63 Debo un reconocimiento especial a los señores James Jensen de Souza-Ferreira y Felipe Voysest Zöllner, colegas del Instituto Peruano de Investigaciones Genealógicas, por haber compartido varios de los datos que figuran en el árbol genealógico siguiente. 



\section{Árbol genealógico de la familia Osambela}

I. D. PEDRo DE Osambela (siglo XVII), dueño de la casa de Osambela en el lugar de Huici, valle de Larraún, reino de Navarra. Casado con Da. María Martina de Recondo. Fueron padres de D. Martín [ver abajo, II].

II. D. MARTín DE OSAMBELA Y RECONDO, casó en Huici, 22-XII-1686, con Da. María de Sucunza [Libro de Matrimonios, $n .^{\circ}$ 1, fol. 9]. Fueron padres de cuatro hijos, que se detallan a continuación.

- II.1. Da. Juana de Osambela y Sucunza, bautizada en Huici, 17-I-1687 [Libro de Bautismos, ${ }^{\circ}{ }^{\circ}$ 1, fol. 26].

- II.2. D. Martín de Osambela y Sucunza, bautizado en Huici, 15-II-1690 [Libro de Bautismos, $n .^{\circ}$ 1, fol. 28]. Falleció de menor edad.

- II.3. D. Martín de Osambela y Sucunza [ver abajo, III].

- II.4. Da. Catalina de Osambela y Sucunza, bautizada en Huici, 22-XII-1697 [Libro de Bautismos, ${ }^{\circ}{ }^{1}$, fol. 32v.].

III. D. MARTÍN DE OSAMBELA Y SUCUNZA, bautizado en Huici, 2-VI-1695 [Libro de Bautismos, $n .^{\circ}$ 1, fol. 31]. Contrajo matrimonio en la misma localidad, el 1-VIII-1723, con Da. Leonora de Arregui (bautizada el 4-IV-1706), hija de D. Martín de Arregui y Da. Graciosa Gorriti, dueños de la casa de Martiperenea [Libro de Matrimonios, $n^{\circ}$ 1, fol. 15].

D. Martín de Osambela y Da. Leonora de Arregui fueron padres de siete hijos, que se detallan a continuación.

- III.1. D. Martín de Osambela y Arregui [ver abajo, IV].

- III.2. D. Juan Francisco de Osambela y Arregui, bautizado en Huici, 28-VI1731 [Libro de Bautismos, n. $^{\circ}$ 1, fol. 58]. Falleció de menor edad.

- III.3. D. Juan Francisco de Osambela y Arregui, bautizado en Huici, 7-VI1733 [Libro de Bautismos, n. $^{\circ}$ 1, fol. 61].

- III.4. D. Pedro Miguel de Osambela y Arregui, bautizado en Huici, 21-IV1736 [Libro de Bautismos, $n .^{\circ}$ 1, fol. 64].

- III.5. D. Juan de Osambela y Arregui, bautizado en Huici, 31-II-1739 [Libro de Bautismos, $n^{\circ}$ 1, fol. 68].

- III.6. D. Martín José de Osambela y Arregui, bautizado en Huici, 5-II-1740 [Libro de Bautismos, $n^{\circ}$ 1, fol. 69].

- III.7. Da. María Bautista de Osambela y Arregui, bautizada en Huici, 9-IV1743 [Libro de Bautismos, n. $^{\circ}$ 1, fol. 74]. 


\section{TEODORO HAMPE MARTÍNEZ}

IV. D. Martín de OSAmbela y ARREGUi, dueño de la casa de Martiperenea, bautizado en Huici, 22-X-1725 [Libro de Bautismos, n. $^{\circ}$ 1, fol. 51]. Casó en la misma localidad, el 12-XI-1753, con Da. María Josefa de Osambela y Azpirroz, hija de D. Juan de Osambela y Da. María Catalina de Azpirroz, dueños de la casa de Recaldea [Libro de Matrimonios, $n .^{\circ} 1$ (II serie), fol. 1]. D. Martín de Osambela y Da. María Josefa de Osambela fueron padres de siete hijos, que se detallan a continuación.

- IV.1. D. Martín de Osambela y Osambela, protagonista de esta monografía [ver abajo, V].

- IV.2. D. Miguel Ventura de Osambela y Osambela, bautizado en Huici, 21-VIII-1757 [Libro de Bautismos, n. $^{\circ}$ 1, fol. 95v.]. Llamado por su hermano mayor, se trasladó al Perú hacia 1780. Otorgó testamento ante Gaspar de Salas en Lima, 11-IX-1812 [Archivo General de la Nación, Protocolos notariales (siglo XIX), $n^{\circ}$ 664, fol. 177].

- IV.3. D. Juan Francisco de Osambela y Osambela, bautizado en Huici, 17-I1760 [Libro de Bautismos, n. $^{\circ}$ 2, fol. 4v.].

- IV.4. D. Pedro Miguel de Osambela y Osambela, dueño de la casa de Martiperenea, bautizado en Huici, 29-VI-1762 [Libro de Bautismos, $n .^{\circ} 2$, fol. 4v.]. Casó en la misma localidad, el 1-VIII-1791, con Da. María Miguel de Iriarte, natural de Huici, hija de D. Juan Pablo de Iriarte y de Da. María Eulalia de Osambela, dueños de la casa de Osambela [Libro de Matrimonios, $n^{\circ} 2$, fol. $19 v$.]. De este matrimonio hubo sucesión.

- IV.5. D. Martín José de Osambela y Osambela, bautizado en Huici, 8-V-1765 [Libro de Bautismos, $n .^{\circ}$ 2, fol. 9].

- IV.6. Da. María Francisca de Osambela y Osambela, bautizada en Huici, 3-XII-1768 [Libro de Bautismos, . $^{\circ}$ 2, fol. 12v.].

- IV.7. D. Miguel Antonio de Osambela y Osambela, clérigo presbítero, bautizado en Huici, 12-VI-1771 [Libro de Bautismos, n. $^{\circ}$ 2, fol. 15].

V. D. Martín de OSAMBela Y OSAMBELA, bautizado en Huici, 29-VIII-1754 [Libro de Bautismos, $n .^{\circ} 1$, fol. 51]. Casó en la Parroquia del Sagrario, Lima, el 14-I-1822, con Da. Mariana Ureta y Bermúdez (natural de Lima), hija de D. José Tadeo Ureta y Da. Isabel Bermúdez [Libro de Matrimonios, 1822, fol. 277]. Testó D. Martín ante Gaspar de Salas en Lima, 21-II-1822 [Archivo General de la Nación, Protocolos notariales (siglo XIX), n. ${ }^{\circ} 669$, fol. 44v.]. Falleció probablemente en el Callao, en 1825.

Da. Mariana Ureta y Bermúdez casó por segunda vez con el Dr. D. José Miguel Berasar, magistrado, con quien tuvo una hija: Da. Tomasa Isabel Berasar y Ureta (nacida en Lima, 21-XII-1831, y muerta en París, 16-V1912), casada en primeras nupcias con Mr. Eugène Albert y en segundas con Mr. Jules Lartigue. Falleció el Dr. D. José Miguel Berasar en Lima, jun. 1843. Da. Mariana otorgó testamento ante José Matías Delgado en Lima, 
DON MARTÍN DE OSAMBELA, COMERCIANTE NAVARRO SIGLOS XVIII/XIX

5-VII-1843 [Archivo General de la Nación, Protocolos notariales (siglo XIX), n. ${ }^{\circ} 968$, fol. 471v.].

D. Martín de Osambela y Da. Mariana Ureta fueron padres de seis hijos, que se detallan a continuación [ver abajo, VI.1. a VI.7.].

VI.1. Da. MARÍA MERCEDES OSAMBELA Y URETA, nació en Lima, 1810, y falleció en la misma ciudad el 16-III-1876 [Parroquia de San Sebastián, Libro de Defunciones, 1876, fol. 176]. Casó en la Parroquia del Sagrario, Lima, el 3-V-1834, con D. José Negrete, natural de Cádiz, residente en el Perú desde aproximadamente 1810 y viudo de Da. Carmen Zevallos (fallecida en Ica en 1822) [Libro de Matrimonios, $n .^{\circ} 12$, fol. 167]. No tuvieron descendencia.

Da. María Mercedes Osambela otorgó testamento cerrado en Lima, 20-VII1874; el cual fue abierto ante Felipe Orellana, luego de su muerte, el 9-V1876 [Archivo General de la Nación, Protocolos notariales (siglo XIX), $n^{\circ} 524$, fol. $235 v$.].

VI.2. Da. MARIANA OSAMBELA Y URETA, natural de Lima. Casó en primeras nupcias en la Parroquia del Sagrario, Lima, el 13-X-1830, con D. José Ignacio Riera y Carmona, natural de San Miguel del Tucumán, hijo de D. Santiago Riera y Da. María Josefa Carmona, residente en el Perú desde aproximadamente 1823 [Libro de Matrimonios, . $^{o}$ 12, fol. 101].$^{64}$ Falleció D. José Ignacio Riera en Lima, en 1834.

Da. Mariana Osambela y D. José Ignacio Riera fueron padres de dos hijos, que se detallan a continuación.

- VI.2.1. D. Francisco Ignacio Riera y Osambela, bautizado el 25-VII-1831 en la Parroquia del Sagrario, Lima [Libro de Bautismos, 1831, fol. 31]. Falleció en Lima, dic. 1836.

- VI.2.2. Da. Juana Rosa Riera y Osambela, casada con Mr. Alexander Prentice (nacido en Greenock, Escocia, 1826, y muerto en Lima, 1-XI-1896), cuyo testamento fue protocolizado ante Carlos Sotomayor en Lima, 14-XI1896 [Archivo General de la Nación, Protocolos notariales (siglo XIX), n. ${ }^{\circ} 807$, fol. 2804]. Da. Juana Rosa Riera y Mr. Alexander Prentice fueron padres de doce hijos:

- VI.2.2.1. D. Alejandro Prentice Riera.

- VI.2.2.2. D. Tomás Prentice Riera, soltero.

- VI.2.2.3. D. Roberto Prentice Riera, casó con Da. Idelmira Kine. Padres de: Da. Teresa Prentice Kine (c.c. Enrique Canaval Bolívar, con sucesión), Da. Esther Prentice Kine (c.c. Eduardo Cárdenas, nat. de Medellín, Colombia), y otros dos más.

64 Fueron padrinos de esta boda don Francisco Araoz y doña Rosa O’Higgins. 
- VI.2.2.4. D. Carlos Prentice Riera, casó con Da. Valentina Herrera. Padres de D. Juan Carlos Prentice Hererra, c.c. Carmen Natalia Cedrón Arbiaga.

- VI.2.2.5. D. Estuardo Prentice Riera, casó con Da. [...] Sevilla.

- VI.2.2.6. Da. Rosa Prentice Riera, casó con D. Ricardo Guillermo Odlum.

- VI.2.2.7. D. Juan Martín Prentice Riera, nacido en 1866, casó con Da. Juana Rebollo Zurita (natural de Tarapacá).

Tuvieron doce hijos, a saber: [1] D. Juan Antonio Prentice Rebollo, c.c. Da. Guillermina Chávez; [2] D. Carlos Prentice Rebollo, c.c. Da. María Teresa Casanova; [3] Da. Rosa Prentice Rebollo, c.c. D. José Munaro; [4] D. Tomás Prentice Rebollo, c.c. Da. Teresa Harman y después c. Da. Zoila Vargas; [5] Da. Genoveva Prentice Rebollo, nacida en 1906, c.c. D. Ricardo J. Rospigliosi Castro; [6] Da. Margarita Prentice Rebollo, c.c. D. Manuel Vásquez de Velasco; [7] Da. Alejandrina Prentice Rebollo, c.c. D. Paul Haaker Fort; [8] Da. Evangelina Prentice Rebollo, fallecida de menor edad; [9] Da. Mariana Prentice Rebollo, fallecida de menor edad; [10] D. Alejandro Prentice Rebollo, fallecido de menor edad; [11] Da. Consuelo Prentice Rebollo, c.c. D. Ricardo Noriega Calmet; [12] D. Guillermo Prentice Rebollo, c.c. Da. Vilma León.

- VI.2.2.8. D. Guillermo Prentice Riera, casó con Da. Rosa Conti.

- VI.2.2.9. D. Manuel Prentice Riera.

- VI.2.2.10. Da. Mercedes Prentice Riera, casó en 1898 con D. Emilio Godoy Agostini.

- VI.2.2.11. Da. María Margarita Prentice Riera, nacida en Londres, 1878, casó en Miraflores (Lima), el 16-V-1897, con D. Manuel Ignacio Reyes Murillo, hijo de D. Juan Manuel Reyes y Da. Eugenia Murillo.

- VI.2.2.12. Da. Ana Prentice Riera, nacida en Londres, casó en Magdalena (Lima), el 18-VI-1898, con D. Carlos Estenós Torres.

VI.3. Da. Mariana OSAmbela Y URETA, natural de Lima. Casó en segundas nupcias en la Parroquia de San Sebastián, Lima, en 1837, con Mr. Thomas Wheelock, comerciante inglés (nacido en Market Drayton, Shropshire, 13-XII-1813, y muerto en Londres, 5-II-1890), hijo de Mr. Thomas Wheelock y Mrs. Elizabeth Wheelock. Falleció Da. Mariana en 5-IV-1888. Da. Mariana Osambela y Mr. Thomas Wheelock fueron padres de ocho hijos, que se detallan a continuación.

- VI.3.1. D. Tomás Wheelock y Osambela, nacido en Lima el 1-II-1840 y bautizado en la iglesia de Santa Rosa de los Padres. Casó con Da. Juana Porras Miota; con sucesión. 
DON MARTÍN DE OSAMBELA, COMERCIANTE NAVARRO SIGLOS XVIII/XIX

- VI.3.2. D. Carlos Enrique Wheelock y Osambela, nacido en Lima el 16-II1841 y bautizado en la Parroquia de San Sebastián. Casó en 1872 con Da. Beatriz Cristina Delgado Martínez, hija de D. José Andrés Delgado y Cotera y Da. María del Carmen Martínez.

Padres de D. Carlos Wheelock Delgado (bautizado el 11-II-1873 en la Parroquia del Sagrario, Lima) y D. Tomás Wheelock Delgado.

- VI.3.3. D. Guillermo Alejandro Wheelock y Osambela, nacido en Lima el 25-VI-1842 y bautizado en la Parroquia de San Sebastián.

- VI.3.4. D. Alejandro Wheelock y Osambela, nacido en Lima el 5-VIII-1843 y bautizado en la Parroquia de San Sebastián. ${ }^{65}$

- VI.3.5. D. Ricardo Wheelock y Osambela, bautizado el 23-V-1847, al año y 10 meses de nacido, en la Parroquia del Sagrario, Lima [Libro de Bautismos, $n .^{\circ}$ 22, fol. 279].

- VI.3.6. D. Enrique María Wheelock y Osambela, bautizado el 23-V-1847, de 14 días de nacido, en la Parroquia del Sagrario, Lima [Libro de Bautismos, n. ${ }^{\circ} 22$, fol. 279]. ${ }^{66}$

- VI.3.7. D. Wilfredo Wheelock y Osambela. Legatario de su tía Da. Dolores Osambela y Ureta por su testamento de 22-VI-1892.

- VI.3.8. Da. Ana María Wheelock y Osambela, bautizada el 22-II-1854, al mes de nacida, en la Parroquia del Sagrario, Lima [Libro de Bautismos, $n$. $^{\circ}$ 24, fol. 37]. Casó con D. José Francisco de Medina, nacido en Chinandega (Nicaragua) en 1842, hijo del banquero D. Crisanto de Medina y de Da. Mercedes Salazar. Falleció Da. Ana María Wheelock en Londres, 3-II-1877.

VI.4. D. JOSÉ VALENTÍN OSAMBELA Y URETA, del gremio de panaderos de Lima, casado con Da. [...] Mansilla. Fueron padres de tres hijos, que se detallan a continuación.

- VI.4.1. Da. Emilia Osambela y Mansilla, casada con D. José Mazzini; con sucesión.

- VI.4.2. D. Belisario Osambela y Mansilla.

- VI.4.3. D. José Manuel Osambela y Mansilla; casado y con sucesión.

VI.5. Da. MARÍA DoloRES OSAMBELA Y URETA, natural de Lima, soltera. Terciaria de la Orden de San Francisco. Otorgó testamento ante Carlos Sotomayor en Lima, 22-VI-1892 [Archivo General de la Nación, Protocolos notariales (siglo XIX), n. ${ }^{\circ}$ 792, fol. 1906v.].

65 Los datos sobre el nacimiento de estos cuatro primeros hijos proceden de Voysest Zöllner, Felipe. "Relación de registros de nacimientos y bautismos cristianos no católicos de descendientes de inmigrantes en Lima y Callao", en Revista del Instituto Peruano de Investigaciones Genealógicas, vol. 19, Lima, 1993, págs. 346-347.

66 En la doble ceremonia del bautizo de Ricardo y Enrique María Wheelock, actuó como padrino el doctor José Maruri de la Cuba, vocal de la Corte Suprema de Justicia.

67 Declararon como testigos en este proceso el coronel Mariano Masías, don Luis Murguía (escribano) y don Juan Francisco Vera y Osambela. 


\section{TEODORO HAMPE MARTÍNEZ}

VI.6. D. CAYETANo OSAMBELA Y URETA, nació en Lima y falleció en la misma ciudad (de pulmonía), el 21-X-1878. Casó en la Parroquia del Sagrario, Lima, el 1-VIII-1855, con Da. Juana Panizo y Pérez, hija de D. José Francisco Panizo y Da. Mercedes Pérez [Libro de Matrimonios, 1855, fol. 85]. Se inició el proceso de intestado de D. Cayetano ante Mariano Terrazas, luego de su muerte, el 12-XII-1878 [Archivo General de la Nación, Protocolos notariales (siglo XIX), $n .^{\circ} 961$, fol. 271$] .{ }^{67}$

D. Cayetano Osambela y Da. Juana Panizo fueron padres de dos hijos, que se detallan a continuación.

- VI.6.1. D. Simón Claudio Osambela y Panizo [ver abajo, VII].

- VI.6.2. Da. Carmen Osambela y Panizo, bautizada el 6-XII-1845, a los 4 meses y 20 días de nacida, en la Parroquia del Sagrario, Lima [Libro de Bautismos, 1845, fol. 212].

VI.7. Da. Juana Osambela Y URETA, nació en Lima, 1823. Casó con D. Juan Bautista Vera y Barreda (nacido en Chiclayo en 1813), hijo de D. Nazario Vera y Da. Francisca Barreda, el cual otorgó su testamento ante Manuel Iparraguirre en Lima, 15-XII-1887 [Archivo General de la Nación, Protocolos notariales (siglo XIX), $n .^{\circ} 304$, fol. 214v.]. Da. Juana otorgó testamento ante Néstor Voysest en Lima, 20-IV-1909 [Archivo General de la Nación, Protocolos notariales (siglo XX), Voysest/n. ${ }^{\circ}$ 12, fol. 263v.].

Da. Juana Osambela y D. Juan Bautista Vera siguieron proceso de divorcio a partir de $1861 .^{68}$ Fueron padres de nueve hijos, que se detallan a continuación.

- VI.7.1. D. Manuel Ruperto Vera y Osambela.

- VI.7.2. Da. María del Carmen Vera y Osambela, bautizada el 20-VII-1844, a los 4 días de nacida, en la Parroquia de los Huérfanos, Lima [Libro de Bautismos, 1844, fol. 67].

- VI.7.3. Da. Francisca Emilia Vera y Osambela, bautizada el 12-X-1845 en la Parroquia de los Huérfanos, Lima [Libro de Bautismos, 1845, fol. 23]. Monja profesa (Sor Emilia) en el convento de las Descalzas de San José.

- VI.7.4. D. Juan Francisco Vera y Osambela, casado con Da. Luisa Álvarez; con sucesión.

- VI.7.5. D. Carlos Máximo Vera y Osambela, bautizado el 24-XI-1851, a los 6 días de nacido, en la Parroquia del Sagrario, Lima [Libro de Bautismos, 1851, fol. 181]. Falleció de menor edad.

- VI.7.6. D. Ricardo Vera y Osambela.

68 AGN, Corte Superior de Lima, Causas civiles, leg. 804, cuad. 10. Aquí declara doña Juana Osambela: "Mi esposo me ha promovido un juicio de divorcio, y en el auto conciliatorio convinimos ante el juez que yo viviese en la casa de mis hermanas [doña Mercedes y doña Dolores] y que me alimentase con cincuenta pesos mensuales que se me pasan por mi haber paterno. También convinimos en que mi marido se quedaría con los hijos varones y en que las hijas fuesen a un monasterio...". 
DON MARTÍN DE OSAMBELA, COMERCIANTE NAVARRO SIGLOS XVIII/XIX

- VI.6.7. D. Eduardo Vera y Osambela.

- VI.7.8. D. Carlos Víctor Vera y Osambela. Falleció de menor edad.

- VI.7.9. Da. Leonarda Livia Vera y Osambela, bautizada el 2-XII-1859 en la Parroquia del Sagrario, Lima [Libro de Bautismos, 1859, fol. 171]. Falleció de pulmonía en Lima, el 1-VII-1864, a los 4 años y 7 meses [Parroquia de Santa Ana, Libro de Defunciones, 1864, fol. 19].

VII. D. Simón ClaUdio OSAmbela Y PANIzo, abogado, nacido el 28-X-1843 y bautizado el 18-I-1844 en la Parroquia del Sagrario, Lima [Libro de Bautismos, 1844, fol. 127]. Casó con Da. Marie Borderes d'Olleron.

Fueron padres de cinco hijos, que se detallan a continuación.

- VII.1. D. Emilio Osambela y Borderes.

- VII.2. Da. Matilde Osambela y Borderes, casó con D. José María Herrera y Quiroz.

Padres de: [1] Da. Lily Herrera y Osambela y [2] D. Raúl Herrera y Osambela, casado con Da. Josefina Oberto-Besso; con sucesión.

- VII.3. Da. Lucila Osambela y Borderes.

- VII.4. Da. Ernestina Osambela y Borderes.

- VII.5. D. José Enrique Osambela y Borderes.

Relación de documentos sobre don Martín de Osambela y sus principales allegados

- Venta enfitéutica del terreno de la casa de Osambela. Otorgada en Lima por fray Joaquín Molleda, maestro prior del convento de Santo Domingo, ante el escribano Justo Mendoza y Toledo, el 16-V-1807.

[Archivo General de la Nación, Protocolos notariales (siglo XIX), n. ${ }^{\circ} 410$, fols. 291-297v].

- Testamento de D. Martín de Osambela, vecino y comerciante en Lima, natural del pueblo de Huici (Navarra). Otorgado en Lima, ante el escribano Gaspar de Salas, el 26-V-1812.

[Archivo General de la Nación, Protocolos notariales (siglo XIX), n. ${ }^{\circ}$ 664, fols. 82v-84].

- Testamento de D. Miguel Ventura de Osambela, residente en Lima, natural del pueblo de Huici (Navarra). Otorgado en Lima, ante el escribano Gaspar de Salas, el 11-IX-1812.

[Archivo General de la Nación, Protocolos notariales (siglo XIX), n. ${ }^{\circ}$ 664, fols. 177-178].

- Testamento de D. Martín de Osambela. Otorgado en Lima, ante el escribano Gaspar de Salas, el 31-VIII-1815.

[Archivo General de la Nación, Protocolos notariales (siglo XIX), n. ${ }^{\circ} 665$, fols. 546-547]. 
- Testamento de D. Martín de Osambela. Otorgado en Lima, ante el escribano Gaspar de Salas, el 2-II-1820.

[Ha sido arrancado del Archivo General de la Nación, Protocolos notariales (siglo XIX), $n .^{\circ} 668$, fols. 24v-26].

- Expediente matrimonial de D. Martín de Osambela y Da. Mariana Ureta, natural de Lima. Procesado ante el vicariato arzobispal de Lima en enero de 1822 .

[Archivo Arzobispal de Lima, Expedientes matrimoniales (enero de 1822), $\left.n^{\circ} 21\right]$.

- Partida de matrimonio de D. Martín de Osambela y Da. Mariana Ureta. Otorgada en Lima, por el padre fray José Santiago Polar, el 14-I-1822. [Parroquia del Sagrario, Libro de Matrimonios, 1822, fol. 277].

- Testamento de D. Martín de Osambela. Otorgado en Lima, ante el escribano Gaspar de Salas, el 21-II-1822.

[Archivo General de la Nación, Protocolos notariales (siglo XIX), n. ${ }^{\circ} 669$, fols. 44v-46].

- Testamento de Da. Mariana Ureta. Otorgado en Lima, ante el escribano Juan Pío de Espinoza, el 19-XI-1827.

[Archivo General de la Nación, Protocolos notariales (siglo XIX), n. ${ }^{\circ}$ 232, fols. 558v-560v].

- Testamento de Da. Mariana Ureta. Otorgado en Lima, ante el escribano José Matías Delgado, el 5-VII-1843.

[Archivo General de la Nación, Protocolos notariales (siglo XIX), $n{ }^{\circ} 968$, registro de Manuel de Uriza, fols. 471v-476].

- Codicilo de Da. Mariana Ureta. Otorgado en Lima, ante el escribano José Matías Delgado, el 6-VII-1843 (en dos entradas).

[Archivo General de la Nación, Protocolos notariales (siglo XIX), n. ${ }^{\circ} 968$, registro de Manuel de Uriza, fols. 476v-477v y 478v-479v].

- Adjudicación de la casa de Osambela a Da. Manuela Mesa. Otorgada en Lima por el doctor Manuel Olivares, juez de primera instancia, ante el escribano Juan Cosio, el 12-VI-1854.

[Archivo General de la Nación, Protocolos notariales (siglo XIX), n. ${ }^{\circ}$ 164, fols. 154v-157].

- Laudo de partición de los bienes de D. Martín de Osambela. Otorgado en Lima por el doctor Antonio Arenas, árbitro componedor, ante el escribano Lorenzo Ordóñez, el 31-III-1870.

[Archivo General de la Nación, Protocolos notariales (siglo XIX), n. ${ }^{\circ} 863$, registro de Félix Sotomayor, fols. 1619-1632]. 